\title{
TRABALHO DIDÁTICO COM TEXTO LITERÁRIO E VISIBILIDADE AFRO-LATINA NAS AULAS DE E/LE: REFLEXÕES SOBRE NOSSA EXPERIÊNCIA NO IFRJ
}

\author{
EDUCATIONAL WORK WITH LITERARY TEXT AND AFRO- \\ LATINA VISIBILITY IN SFL CLASSES: REFLECTIONS ON OUR \\ EXPERIENCE IN IFRJ
}

\author{
Paula Fernanda Vicente Rosa *
}

\begin{abstract}
Resumo: O ensino de Espanhol como Língua Estrangeira (E/LE) ministrado na esfera da Educação Profissional e Tecnológica (EPT) é particularmente atravessado por visões restritas acerca de suas finalidades. Somado a isso, temos uma educação fortemente marcada pelo racismo epistêmico e pela naturalização das vozes dominantes. No presente artigo, tomaremos como base uma atividade desenvolvida com turmas de $1^{\circ}$ ano do Ensino Médio Integrado do IFRJ, a fim de pensarmos os desafios enfrentados na busca por uma formação humana integral, comprometida com a visibilidade de identidades historicamente secundarizadas. Esta atividade tem como cerne o texto literário e a predominância de mulheres afro-latinas, o que nos levará a questionar, sobretudo, dois (não) lugares: o da literatura nas aulas de língua espanhola e o das produções de autoria negra. Situando mulheres negras como sujeitos do conhecimento, refletiremos sobre aprendizagem antirracista de E/LE e seus impactos na formação crítica e afirmativa dos estudantes.

Palavras-chave: Ensino-aprendizagem de E/LE. Educação Profissional e Tecnológica. Ensino Médio Integrado. Literatura de autoria negra. Antirracismo.
\end{abstract}

\begin{abstract}
The teaching of Spanish as a Foreign Language (SFL) for Technical and Vocational Education and Training (TVET) classes is particularly marked by restrict views on its purposes. Also, there is an education strongly marked by epistemological racism and by the naturalization of domineering voices. In this paper, we use as a base an activity developed with freshman classes of professional qualification integrated to secondary education in IFRJ, for thinking about the challenges faced on the pursuit of an integral human education, committed to the visibility of historically secondary identities. This activity has in its core the literary text and the predominance of Afro-Latina women, which makes us question mainly two (non) places: that of literature in Spanish classes and that of black authorship works. Setting black women as protagonists in knowledge production, we reflected on antiracist leaning of SFL and its impacts on the students' critical and affirmative education.

Keywords: Spanish Teaching and Learning. Technical and Vocation Education and Training. Professional Qualification Integrated to Secondary Education. Black Authorship Literature. Anti-racism.
\end{abstract}

\section{Introdução}

Entendemos que o ensino de Espanhol como Língua Estrangeira (E/LE) e, por conseguinte, o trabalho com literaturas de língua espanhola são atravessados por relações sociais e culturais assimétricas que perpetuam divisões de território, de gênero e, sobretudo, raciais ao longo da história. Desse modo, é fundamental que o currículo e as aulas de E/LE sejam constantemente repensados, de modo a garantir uma formação

\footnotetext{
* Professora de Língua Espanhola, Língua Portuguesa e respectivas Literaturas no Instituto Federal de Educação, Ciência e Tecnologia do Rio de Janeiro (IFRJ). Mestra em Literatura Brasileira pela Universidade do Estado do Rio de Janeiro (UERJ). Graduada em Letras Português/Espanhol pela mesma universidade (UERJ). E-mail: paula.rosa@ifrj.edu.br
} 
emancipadora, descolonizada, capaz de reiterar a visibilidade e o status de sujeito dos indivíduos negros.

Este trabalho pretende desdobrar algumas reflexões críticas acerca da repercussão de uma experiência pedagógica ocorrida durante as aulas de Espanhol Aplicado ao Turismo I, no Instituto Federal de Educação do Rio de Janeiro (IFRJ), campus Resende. Tal experiência está associada à proposição de uma atividade didática que tem como eixo a literatura de autoria feminina afro-latina.

Para abordarmos o desenvolvimento desta tarefa, será preciso elucidar que nossa intenção é pensar a pertinência deste tipo de prática pedagógica dentro do ensino de E/LE no âmbito da Educação Profissional e Tecnológica (EPT), uma vez que as visões sobre tal ensino fazem parte de um processo marcado por disputas de concepções que reverberam tanto na trajetória de formação dos sujeitos quanto nas suas percepções sobre a função da escola.

Em seguida, realizaremos cuidadosa análise da referida atividade que, conforme mencionamos, tem a autoria negra feminina como estruturante e seu ponto central está na análise interpretativa do poema Me gritaron negra, da escritora peruana Victoria Santa Cruz (1922-2014). Com esta poesia, verificaremos a projeção de uma linguagem literária que denuncia estereótipos e expressões discursivas de discriminação comuns à experiência afrodiaspórica ${ }^{1}$. A partir da sugestão de diálogo entre a poesia e a produção intelectual de outras autoras negras latino-americanas e caribenhas, procuraremos introduzir a resistência afrodescendente em um contexto amplo que aproxima historicamente negras e negros da América Latina e Caribe, compreendendo que formamos um conjunto de países com percursos e problemáticas semelhantes.

Tendo em vista que o racismo, "mais do que estar na estrutura das relações sociais, determina estas relações" (KILOMBA, 2019, p. 71), avaliaremos como o ensino de E/LE também pode estabelecer o colonialismo e a secundarização negra, posto que o racismo estrutural marca a educação escolar brasileira. Assim, explicitaremos a necessidade de trabalharmos por uma educação antirracista a partir da desarticulação das relações raciais de poder que permeiam a epistemologia literária do ensino de Espanhol.

Cientes de que o ambiente escolar não é neutro, devemos admitir que o direito da fala tem sido negado a determinadas identidades, sobretudo àquelas que entrecruzam estruturas de opressão. Cabe ressaltar, portanto, que a elaboração da tarefa a que vamos nos ater faz parte de um empenho contínuo em situar homens e mulheres negras como sujeitos da intelectualidade e do conhecimento que devem ser legitimados pela escola. A partir da atividade pedagógica exemplificada, reafirmaremos, por fim, as aulas de E/LE no Curso Técnico Integrado ao Ensino Médio - como parte importante dessa formação de consciência libertadora e de postura afirmativa daquelas/es atravessadas/os pelas identidades afro-latinas.

\footnotetext{
${ }^{1} \mathrm{O}$ termo "diáspora" está relacionado à dispersão. Refere-se ao deslocamento, forçado ou não, de povos pelo mundo. Como latino-americanos, nos interessa destacar a diáspora africana, nome dado ao fenômeno caracterizado pela imigração forçada de africanos negros, durante o tráfico transatlântico de escravizados. Devido a tal processo, temos um grande contingente de pessoas de origem africana vivendo fora do continente e integrando as sociedades que se formaram nos locais de destino de seus antepassados, são os/as afrodiaspóricos/as.
} 
10 que isso tem a ver com ensino de Espanhol? Contexto e desdobramentos da pergunta

Como toda prática pedagógica é social, histórica e geograficamente situada, nos cabe primeiramente especificar o contexto em que o trabalho foi desenvolvido: trata-se de uma tarefa proposta na aula de Língua Espanhola, para alunos brasileiros do $1^{\mathrm{o}}$ ano do Ensino Médio Integrado ao Curso Técnico em Guia de Turismo, do Instituto Federal de Educação do Rio de Janeiro (IFRJ), campus avançado Resende.

Resende é uma cidade localizada no interior do Estado do Rio de Janeiro, na região Sul-fluminense. Está a 168 quilômetros de distância da capital e tem população estimada em 126.923 habitantes, segundo censo do IBGE de 2017. Seu território faz divisa com os Estados de São Paulo e Minas Gerais, além dos limites com outros municípios do Rio, como Barra Mansa, Itatiaia, Porto Real e Quatis. Desde 1943, Resende abriga a sede do maior complexo militar da América Latina, a Academia Militar das Agulhas Negras (AMAN), responsável pela formação de oficiais combatentes do Exército Brasileiro.

A economia de Resende e adjacências gira, atualmente, em torno do status de polo industrial, automotivo, metalúrgico e de produtor de energia nuclear. O Turismo é um mercado em potencial crescimento na localidade. O campus do Instituto Federal instalado desde 2015, seja na modalidade concomitante/subsequente ou integrada ao Ensino Médio, oferece cursos técnicos que oportunizam aos estudantes - trabalhadores ou futuros trabalhadores - a exploração das possibilidades industriais e turísticas existentes na região. Assim, os cursos oferecidos são os de Técnico em Segurança do Trabalho (apenas no modo concomitante/subsequente) e Técnico em Guia de Turismo (nas duas modalidades citadas).

É preciso considerar que a cultura militar impacta significativamente a dinâmica das relações nesta cidade. Por sua vez, a perspectiva industrial produtivista - comum ao panorama global e alimentada pelas ideologias neoliberais - está bastante assentada no imaginário local, favorecida, inclusive, pelo campo de empregos geralmente ofertados na região.

Nesse contexto, nasce a pergunta: "O que isso tem a ver com ensino de Espanhol?” A indagação foi feita a mim, professora responsável pela disciplina de Espanhol Aplicado ao Turismo I, por uma mãe de dois estudantes do $1^{\circ}$ ano do Ensino Médio. Seu questionamento surge após analisar o trabalho que os filhos haviam levado para casa. Em tom preocupado e um tanto quanto indignado, a responsável me fez a pergunta supracitada em uma reunião de pais. Esta mãe se referia à tarefa que, além de explorar a interpretação de texto literário, objetivava gerar reflexões acerca de racismo e resistência negra a partir do diálogo entre autoras negras latino-americanas.

Tal indagação, que demarca a importante repercussão da atividade, é mote para lançarmos um olhar diligente sobre os desafios pedagógicos existentes frente à persistência de visões limitadas em relação aos papéis da Educação Profissional e Tecnológica, bem como sobre o ensino de Língua Espanhola nesse contexto, pois, mais do que mera curiosidade, a pergunta desta mãe carregava em si uma série de ressentimentos pela quebra de algumas expectativas preexistentes.

Após conversar com a responsável, foi possível verificar também que sua visão deslegitimava o lugar do ensino de literatura nas aulas de E/LE, além de equivocadamente pressupor um suposto espaço destinado à educação das relações 
étnico-raciais que não necessariamente o das classes de língua estrangeira. Essas são perspectivas restritas com as quais os professores de E/LE, sobretudo os de cursos técnicos e profissionalizantes integrados ao Ensino Médio, costumam lidar. Tais noções, bastante difundidas no senso comum, integram um modo bastante conservador de dizer e pensar o ensino de línguas estrangeiras que exclui quaisquer outras possibilidades de atuação docente, como se língua só pudesse ser trabalhada como um fim em si mesma.

Portanto, mais do que estarmos seguros de que a atividade em questão se alinha às orientações educacionais norteadoras do nosso trabalho, tanto com relação aos papéis da EPT, quanto no que tange ao ensino de línguas estrangeiras neste âmbito, nos cabe também enfatizar a necessidade de pensarmos os conhecimentos e discussões que têm, ou não, feito parte das agendas escolares. A Educação Básica, nesse sentido, não é um campo apolítico, mas sim uma esfera capaz de afirmar relações de poder que reproduzem ideias e metodologias dominantes, além de ditar os saberes, temáticas e vozes que devem ou não fazer parte do ensino-aprendizagem escolar. Romper com concepções excludentes de educação faz parte de nossa função docente e de nosso compromisso com a formação de sujeitos plenos.

\subsection{Desafios do ensino de E/LE na Educação Profissional e Tecnológica}

Segundo Eneida Shiroma e Domingos Filho (2011, p.728), a formação profissional e técnica destinada aos trabalhadores ou futuros trabalhadores caracterizouse, desde suas origens, pela "terminalidade em níveis elementares da escolarização", configurando moldes educacionais de "adestramento" para a função laboral. Fruto da cultura produtivista, esta formação instrumental negligenciava a sociabilidade humana e tomava os conhecimentos para o mercado como propósitos únicos. Mas, o mercado deve ser o limite da educação? Respondendo de forma negativa a essa pergunta, temos a superação do marco legal-institucional que separava EPT e Educação Básica. O decreto n. 2.208/97 reestabelece a possibilidade da organização curricular integrada entre educação profissional e educação geral, no âmbito do Ensino Médio. Tal integração aponta para novos horizontes de ensino-aprendizagem, pensados de modo a conceber uma educação cidadã completa.

Embora a escola ainda precise se contrapor às remanescentes perspectivas instrumentais da formação, atualmente a EPT - e neste âmbito os Institutos Federais insere-se como parte da construção de projetos para a sociedade como um todo. Seu currículo deve estar assentado na concepção de formação humana integral, de modo a contemplar trabalho, ciência, tecnologia sem olvidar reflexões e problematizações acerca da cultura, da arte, favorecendo o exercício do pensamento crítico e criando condições de autonomia intelectual e ética.

$\mathrm{O}$ ensino de E/LE deve estar vinculado aos propósitos anteriormente mencionados. No entanto, este ensino há anos vem sendo condicionado pela escola e pelos cursos de idiomas às metodologias tradicionais de base estruturalista, focadas na aquisição de hábitos linguísticos e na automatização destes hábitos. A concepção de língua como sistema pronto e acabado é responsável pelo predomínio das propostas de atividades centradas na memorização, na aprendizagem de códigos, vocabulários e regras gramaticais. Romper com esta compreensão de língua e, portanto, de ensinoaprendizagem de línguas estrangeiras costuma causar estranhamento na comunidade escolar. Nesse sentido, “o que isso tem a ver com ensino de Espanhol?" também implica 
suposições sobre o ensino-aprendizagem de E/LE e sobre a função deste ensino que não foram endossadas pelo tipo de trabalho entregue aos estudantes.

Ao inserirmos um poema e explorarmos o caráter eminentemente social dos enunciados, as metáforas e os efeitos de sentido criados na lírica da produção, tiramos o foco das tradicionais tarefas que valorizam o conteudismo e a memorização de códigos descontextualizados para dar lugar a atividades que ajudam a compreender e avaliar os discursos produzidos nas diferentes sociedades e práticas letradas (cf. PCNs, 1998). É preciso entender a língua como produtora de realidades e imagens sociais não fixas ou neutras. A aprendizagem e o uso devem caminhar juntos.

Desse modo, aprender Espanhol na EPT significa também refletir sobre o uso que as pessoas fazem deste idioma ao agirem na sociedade (c.f. OCEMs, 2006). O ensino de E/LE deve educar para a leitura e para o entendimento de que é na e pela língua que reconhecemos, construímos, desconstruímos e reelaboramos noções existentes no mundo. Como veremos, ao ser chamada de negra, o eu-lírico da poesia de Victoria Santa Cruz acaba por afrontar os significados sociais dados pela ideologia racista. Tratase de um embate que se dá no plano do discurso e que reestabelece o real lugar da identidade negra. Por esse e outros motivos que mencionaremos, a atividade proposta tem a ver com ensino de Língua Espanhola, quando compreendemos língua sob uma perspectiva discursiva, salientando o processo de produção de sentidos, de modo que os saberes se façam objeto de uma construção coletiva a qual conduza à competência leitora crítica, consciente e antirracista.

\section{$1.2 O$ (não) lugar das literaturas de autoria negra nas aulas de $\mathrm{E} / \mathrm{LE}$}

Se a escola deve assumir o compromisso de reiterar a inserção dos educandos no universo da liberdade, do conhecimento, das artes e das letras, isso significa que, além de as aulas de E/LE se responsabilizarem pelo desenvolvimento da competência leitora, também devem se prestar à evolução da competência literária.

Textos literários possuem características específicas e exigem uma postura interpretativa por parte do leitor, diferente daquela solicitada por gêneros não-literários. A literatura estabelece novas relações com o mundo, gera novas realidades. $\mathrm{O}$ trabalho com o literário auxilia na formação de um estudante apto a compreender que língua também é espaço de criação dentro do qual ele pode se aventurar (cf. SANTOS, 2007).

A partir do empenho estético com a linguagem, a poeta Victoria Santa Cruz, por exemplo, foi capaz de produzir novas e diferentes relações entre expressões e suas acepções. Mostra disso é o trânsito de sentidos assumidos pela palavra negra/negro ao longo do poema proposto para os alunos. Interpretar novos emaranhados de significação, analisar as estratégias utilizadas pelos literatos no lavor artístico com a língua e estar sensível à construção e compreensão dos valores metafóricos de palavras, textos e obras literárias são habilidades necessárias que precisam ser favorecidas na escola, a partir da familiaridade do educando com a literatura.

Ana Cristina Santos (2007, p.34) afirma que, "a lo largo de la historia de la enseñanza de Español como Lengua Extranjera, se subutilizan los textos literarios." Além de serem pouco acolhidos pelos professores e aparecerem em número reduzido nos materiais didáticos - quando comparados aos demais textos -, os gêneros literários normalmente não são trabalhados por seu valor estético, não sendo, portanto, tratados 
em diferença com relação àqueles que não pretendem explorar o potencial artístico da linguagem.

Também acreditamos que a visão utilitarista de ensino-aprendizagem é uma das principais responsáveis pelo pouco ou nenhum espaço dedicado aos textos de literatura hispânica nas classes de E/LE. Como vimos, a Educação Profissional e Tecnológica no Brasil esteve durante muito tempo limitada às pretensões instrumentais do ensino para o trabalho, negligenciando conteúdos que não estivessem direta e explicitamente vinculados ao exercício laboral. No entanto, como já advertimos, trata-se de uma ideia de educação que necessita ser suplantada.

Ademais, retomando Ana Cristina Santos (2007), observamos que as metodologias estruturalistas impactam sobremaneira na forma como os textos literários vêm sendo historicamente trabalhados: olvidando a análise estética e servido simplesmente como um recurso a mais para a prática de temas de escrita, conversação, exploração de vocabulário, regras de gramática ou mostra de cultura.

Diante desse cenário, imaginamos que a pergunta "o que isso tem a ver com ensino de Espanhol?", feita pela responsável, demonstra não apenas o estranhamento pela presença de texto literário na atividade proposta a estudantes da EPT, mas também um estranhamento com relação à forma como este texto estava sendo explorado. Contrariando a prática do uso de textos literários como pretextos para exercícios de base estruturalista e/ou exemplos culturais, investimos na abordagem efetiva da interpretação literária, na solicitação não apenas dos conhecimentos linguísticos, mas dos conhecimentos genéricos e de mundo, na realização da análise poética e no estabelecimento de relações entre leituras propostas.

O desenvolvimento da competência literária nas aulas de Espanhol para a EPT não pode ser menosprezado. Entretanto, consideramos extremamente necessário que a superação da subutilização do texto literário seja acompanhada da superação da invisibilidade de escritores cujas identidades não são hegemônicas.

$\mathrm{O}$ apagamento de determinadas autorias é fruto daquilo que chamamos de racismo epistêmico, uma das consequências do racismo estrutural: a produção intelectual e criativa de mulheres negras e homens negros do Brasil e do exterior é ignorada. Assim, os saberes concebidos e as artes produzidas por estes sujeitos permanecem fora do ambiente escolar. Apesar da mencionada secundarização dos textos literários, quando pensamos os autores e autoras de literaturas hispânicas que esporadicamente nos são apresentados nas aulas de E/LE, temos nomes como Miguel de Cervantes, Gabriel García Marques, Isabel Allende, Pablo Neruda, Quino, Eduardo Galeano etc. Mas quantos desses literatos oportunizados nas classes de E/LE são negros? Ora, negros de países de língua espanhola não produzem literatura?

Admitindo que os conhecimentos produzidos e veiculados nos espaços escolares não contemplavam aqueles gerados por determinado conjunto da população, a lei brasileira 10.639/2003 estabelece a obrigatoriedade do ensino de história e culturas afrobrasileiras e africanas nas escolas. Fruto da luta da comunidade negra por reconhecimento e afirmação de direitos no que tange à Educação, tal lei pressupõe a descolonização e democratização dos currículos, das bibliografias e das práticas educacionais. No caso da disciplina de Espanhol como Língua Estrangeira, que, como já pontuado, também é espaço legítimo de trabalho com literatura, entendemos que a visibilidade e a recorrência da autoria negra é uma das possíveis formas de nós, professores de Espanhol, estarmos comprometidos com a efetividade desta lei no Brasil. 
Para Grada Kilomba:

Ter o status de sujeito significa que, por um lado, indivíduos podem se encontrar e se apresentar em esferas diferentes da intersubjetividade e realidades sociais e, por outro lado, podem participar em suas sociedades, isto é, podem determinar os tópicos e anunciar os temas e agendas das sociedades em que vivem. Em outras palavras, elas/eles podem ver seus interesses individuais e coletivos reconhecidos, validados e representados oficialmente na sociedade - o status absoluto de sujeito (KILOMBA, 2019, p. 74).

Compreendendo que o currículo é espaço de disputas, importa garantir a presença negra, bem como a presença de temáticas relevantes aos sujeitos negros nos tópicos pedagógicos, tanto no que se refere ao ensino da Língua Espanhola quanto no que diz respeito ao ensino de literatura produzida nesta língua. Educar para as relações étnico-raciais também significa "romper com o silêncio instituído para quem foi subalternizado" (RIBEIRO, 2017, p.90). Considerar que, historicamente, o ensino de E/LE também está inserido numa realidade curricular excludente é o primeiro passo para as ações de transformação desta situação.

2 A atividade: justificando nossas escolhas

A fim de contribuir para o desenvolvimento da consciência sócio-histórica dos estudantes, consideramos que as produções da América de língua espanhola devem ser privilegiadas nas aulas de E/LE em relação às da península. Entendemos que operar a visibilidade latino-americana e caribenha para alunos brasileiros pode propiciar a percepção de nossa riqueza como povo e contribuir ao intento de descolonização dos saberes (cf. PARAQUETT, 2013).

A escolha da autoria feminina negra, por sua vez, traz ao centro um perfil que, na cena escolar, costuma estar ainda mais ausente que outros: apagamento com o qual desejamos romper. Nesse sentido, situar mulheres afro-latinas como seres ativos cultural, histórica e intelectualmente faz com que as classes de Espanhol rompam com óticas supremacistas em relação a território, gênero e raça.

Apontar para a América hispânica nas aulas de E/LE gera uma excelente oportunidade de nos aproximarmos dos nossos vizinhos e de nos reconhecermos como parte de um mesmo grupo que, apesar das diferenças, possui narrativas, encantos e desafios semelhantes. Assim, a seleção das autoras presentes na tarefa deu-se também no sentido de contribuir para a noção de que determinadas questões levantadas pela comunidade negra no Brasil - e, neste caso, mais especificamente pelas mulheres negras - fazem parte de um coro empreendido por outras mulheres negras dos demais países da América Latina, em distintos momentos. A diáspora africana marca significativamente a formação de quase todo o continente. Dessa forma, o intuito é fazer perceber que não estamos sós e que certas questões de interesse são comuns a toda uma comunidade de história similar, ultrapassando fronteiras nacionais.

Optamos por mulheres latino-americanas que através de suas produções literárias, reflexões e biografias contribuíram ou contribuem deliberadamente para [re]pensar o feminino racializado e endossar a emancipação negra. É certo que nossas opções na elaboração de qualquer atividade estão associadas diretamente aos nossos objetivos pedagógicos. Nossa principal finalidade era explorar a interpretação lírica, de 
modo que os estudantes pudessem ser capazes de reconhecerem-se como sujeitos ativos na compreensão e produção de sentidos em texto poético. Entretanto, desejamos explicitar que este propósito geral veio acompanhado de uma série de escolhas relevantes, contextualizáveis e que endossavam finalidades que consideramos tão necessárias e importantes quanto aquilo que fora estabelecido como objetivo central.

Assim, nos mobilizamos em torno do desmantelamento de padrões dominantes em relação às tarefas, à escola, aos discursos e aos corpos que costumam preponderar no ensino de literatura durante as aulas de E/LE. Dessa forma, ao pensarmos a atividade, refletimos conscientemente sobre perfis identitários que desejávamos visibilizar, além das temáticas que tomaríamos como importantes. De nossa parte, compreendemos que determinados assuntos passam a ser devidamente encarados como relevantes quando nos empenhamos em não mais silenciá-los no ambiente escolar e quando não ignoramos aquelas e aqueles que os afiançam.

Almejamos que o trabalho docente seja fruto de uma série de redefinições nos mais diversos níveis, o que atravessa não só as macropolíticas educacionais, mas as opções que realizamos ao elaborarmos as atividades didáticas, desde os temas considerados relevantes, às identidades não mais deixadas à margem. Portanto, aquilo que exemplificaremos aqui é apenas parte do que desejamos para a educação formal: que o trabalho pedagógico, político e didático esteja comprometido com todas as vozes.

\subsection{Quem são as autoras que figuram na atividade?}

O fio condutor da atividade é o poema musicado Me gritaron negra, de Victória Santa Cruz. Nascida em La Vitoria, província de Lima, Peru, em 1922, era de uma família de pessoas ligadas à arte. Além de poeta, se destacou como acadêmica, coreógrafa, compositora e atriz, criando um dos primeiros grupos teatrais inteiramente composto por pessoas negras, no país. Segundo Ricardo Ferreira (2016), professor da Escola de Comunicação e Arte da Universidade de São Paulo (USP), os estudos e os trabalhos de Victoria Santa Cruz alcançam grande importância por lançarem luz às identidades negras, bastante negligenciadas em tais contextos. A poeta difunde a diversidade da cultura afro-peruana, não só em seu país, mas em quase toda a América. É com base na poesia mais emblemática desta autora que temos os momentos de préleitura e de leitura da atividade.

Em discurso não-literário, porém consonante com aquilo que fora entoado pelo eu-lírico do poema lido, trouxemos o aporte teórico da brasileira Djamila Ribeiro, Mestra em Filosofia e ativista. Além dos livros lançados, a filósofa utiliza as redes sociais como ferramenta para popularização do debate antirracista. Pela relevância que tem no Brasil e pelo grande apelo que exerce nas fontes digitais, imaginamos ser interessante apresentá-la aos jovens estudantes. A citação das palavras de Djamila segue integrando a segunda parte do momento de leitura.

Como pós-leitura, sugerimos aos estudantes a pesquisa de poetas como Virginia Brindis de Salas (Uruguai), Shirley Campbell (Costa Rica), Nancy Morejón (Cuba) e Mary Grueso Romero (Colômbia). A obra de cada uma dessas escritoras nos mostra de modo bastante elucidativo como, não só pela literatura, mas também através da literatura, podemos pensar as relações sociais e culturais assimétricas, o lugar da mulher 
negra, a beleza da ancestralidade africana, a percepção positiva ${ }^{2}$ da negritude etc. Embora muito distintas entre si, embora suas produções se façam em diferentes épocas e países, Victoria Santa Cruz e as poetas recomendadas para investigação assemelham-se no desmantelamento do colonialismo ao reposicionarem os sujeitos negros no contexto latino-americano e caribenho.

Não por acaso, todas essas poetas atuam na superação do racismo, do sexismo e na afirmação da identidade afrodescendente. Cada uma, a seu modo, demonstra também a capacidade de operar o trânsito entre conhecimento nascido na cultura popular, saber acadêmico e arte literária, encarnando no trabalho literário e no não-literário a complexidade da [auto]imagem negra. Assim, tanto na vida como na lírica (no caso exclusivo das poetas), podemos dizer que as mulheres que figuram na atividade souberam endossar a possibilidade de, em sociedades tão desiguais e tão violentas, verem as vítimas de opressão serem convertidas em atores políticos que protagonizam a resistência e a luta.

Apesar de multitalentosas, raramente ouvimos falar de algumas dessas poetas no Brasil. Certamente, este desconhecimento é fruto do bloqueio enfrentado por determinadas identidades secundarizadas na nossa sociedade. A sobreposição destas identidades, conforme já aludido, intensifica o apagamento. Afinal, são mulheres, são latino-americanas e são negras. $O$ gênero, o território e a raça certamente explicam o problemático [não] lugar de seus legados e contribuições entre nós.

Desse modo, também pensamos ser muito poderosa a introdução da imagem de cada uma destas mulheres. No livro Olhares negros: raça e representação, bell hooks (2019, p.33) afirma que "os supremacistas brancos reconheceram que controlar as imagens é central para a manutenção de qualquer sistema de dominação". O mundo real da criação da imagem é político. Se observamos com atenção a forma como as representações dos sujeitos negros são introduzidas nas mais diversas mídias, bem como os espaços nos quais estas representações estão presentes, não será difícil reconhecer a reiterada desumanização de nossos corpos, as representações odiosas de nós, as condições desvalorativas etc.

Por outro lado, em circunstâncias que envolvem posição de poder, exemplificação do belo, lugares de conhecimento e demais situações enaltecedoras, os corpos negros estão ausentes, quando não embranquecidos, como no famigerado caso da figura do escritor Machado de Assis nos livros didáticos.

Descolonizar a educação é também desnaturalizar as imagens que consumimos. É disputar no campo das representações e estar atento ao que fazemos ou não com elas, ao que tornamos visível ou invisível nos materiais didáticos que preparamos pois, como escreveu bell hooks (2019, p.40), "a menos que transformemos as imagens da negritude, das pessoas negras, nossos modos de olhar e as formas como somos vistos, não poderemos fazer intervenções radicais fundamentais que alterem a nossa situação." Por isso, fizemos questão de introduzir a foto de cada uma das escritoras citadas para que nossos estudantes se habituem a associar as imagens de pessoas negras - neste caso mais particularmente as imagens de mulheres negras - a saberes validados, dentro e fora da

\footnotetext{
${ }^{2}$ Segundo Grada Kilomba (2019), no mundo conceitual branco, a negritude é identificada a algo "ruim" e negativo. A autora acredita que, apenas as imagens positivas do povo negro, o que não significa "idealizadas", são capazes de desmantelar a alienação gerada pela percepção colonialista. Kilomba aponta a literatura e a cultura visual como campos fundamentais de construção desta visão positiva da negritude.
} 
escola. Os corpos negros também precisam ser lidos como acadêmicos, artísticos, científicos e intelectuais.

\subsection{As questões propostas para a tarefa}

Conforme anteriormente mencionado, o trabalho didático desenvolvido com as turmas de $1^{\circ}$ ano do Ensino Médio Integrado ao Curso Técnico em Guia de Turismo realizou-se a partir da análise do poema Me gritaron negra. Trata-se de uma potente poesia musicada, recitada de forma performática pela autora Victoria Santa Cruz. Portanto, vale pontuar que, a princípio, os estudantes estão diante de um texto cujo suporte é audiovisual, embora recebam a versão escrita do poema na atividade. No vídeo, a performance é composta pela poeta e por um corpo teatral que a acompanha em coro, percussão, coreografia e expressões físicas.

No texto, o eu-lírico relata sua experiência com o racismo, algo que influencia em sua autoimagem. Interessa observar que, em ambos os suportes - escrito e audiovisual -, o poema explora os sentidos da palavra negra/negro e introduz o corpo da mulher negra como matéria capaz de narrar uma história constituída de negação, proposição e revalorização.

Exporemos agora os textos da atividade e, na sequência, as questões propostas aos estudantes. Ao longo desta seção, mencionaremos as perguntas do trabalho de modo a suscitar o porquê de sua importância para a análise crítico-literária. Assim, realizaremos uma breve análise do poema, a fim de levantarmos possibilidades de leitura que podem ser exploradas durante as aulas, junto aos estudantes, na interpretação textual.

\begin{tabular}{|c|c|c|}
\hline $\begin{array}{l}\text { nas, } \\
\text { iquiera. }\end{array}$ & $\begin{array}{l}\text { ¡Negra! ¡Negra! ¡Negra! } \\
\text { ¡Negra! } \\
\text { ¡Negra! ¡Negra! ¡Neeegra! } \\
\text { ¡Negra! ¡Negra! ¡Negra! } \\
\text { ¡Negra! } \\
\text { ¡Negra! ¡Negra! ¡Negra! } \\
\text { ¡Negra! } \\
\text { Y pasaba el tiempo, } \\
\text { y siempre amargada } \\
\text { Seguía llevando a mi espalda } \\
\text { mi pesada carga } \\
\text { ¡Y cómo pesaba! ... } \\
\\
\text { Me alacié el cabello, } \\
\text { me polveé la cara, } \\
\text { y entre mis entrañas siempre } \\
\text { resonaba } \\
\text { la misma palabra } \\
\text { ¡Negra! ¡Negra! ¡Negra! } \\
\text { ¡Negra! } \\
\text { ¡Negra! ¡Negra! ¡Neeegra! }\end{array}$ & $\begin{array}{l}\text { ¿Y de qué color? NEGRO } \\
\text { ¡Y qué lindo suena! NEGRO } \\
\text { ¿Y qué ritmo tiene? } \\
\text { NEGRO NEGRO NEGRO } \\
\text { NEGRO } \\
\text { NEGRO NEGRO NEGRO } \\
\text { NEGRO } \\
\text { NEGRO NEGRO NEGRO } \\
\text { NEGRO } \\
\text { NEGRO NEGRO NEGRO } \\
\text { Al fin comprendí AL FIN } \\
\text { Ya no retrocedo AL FIN } \\
\text { Y avanzo segura AL FIN } \\
\text { Avanzo y espero AL FIN } \\
\\
\text { Y bendigo al cielo porque quiso } \\
\text { Dios } \\
\text { que negro azabache fuese mi } \\
\text { color } \\
\text { Y al fin comprendí AL FIN } \\
\text { Ya tengo la llave }\end{array}$ \\
\hline
\end{tabular}

${ }^{3}$ Disponível em: https://www.youtube.com/watch?v=g52jzCTUKXA Acesso em: 30 maio. 2020 
me gritaron ¡Negra!

¡Negra! ¡Negra! ¡Negra!

¡Negra! ¡Negra! ¡Negra!

“Soy acaso negra?” - me dije

“¿Qué cosa es ser negra?

¡Negra!

Y yo no sabía la triste verdad que aquello escondía. ¡Negra!

Y me sentí negra, ¡Negra!

Como ellos decían ¡Negra!

Y retrocedí ¡Negra!

Como ellos querían ¡Negra!

Y odié mis cabellos y mis labios gruesos

y miré apenada mi carne

tostada

Y retrocedí ¡Negra!

Y retrocedí...

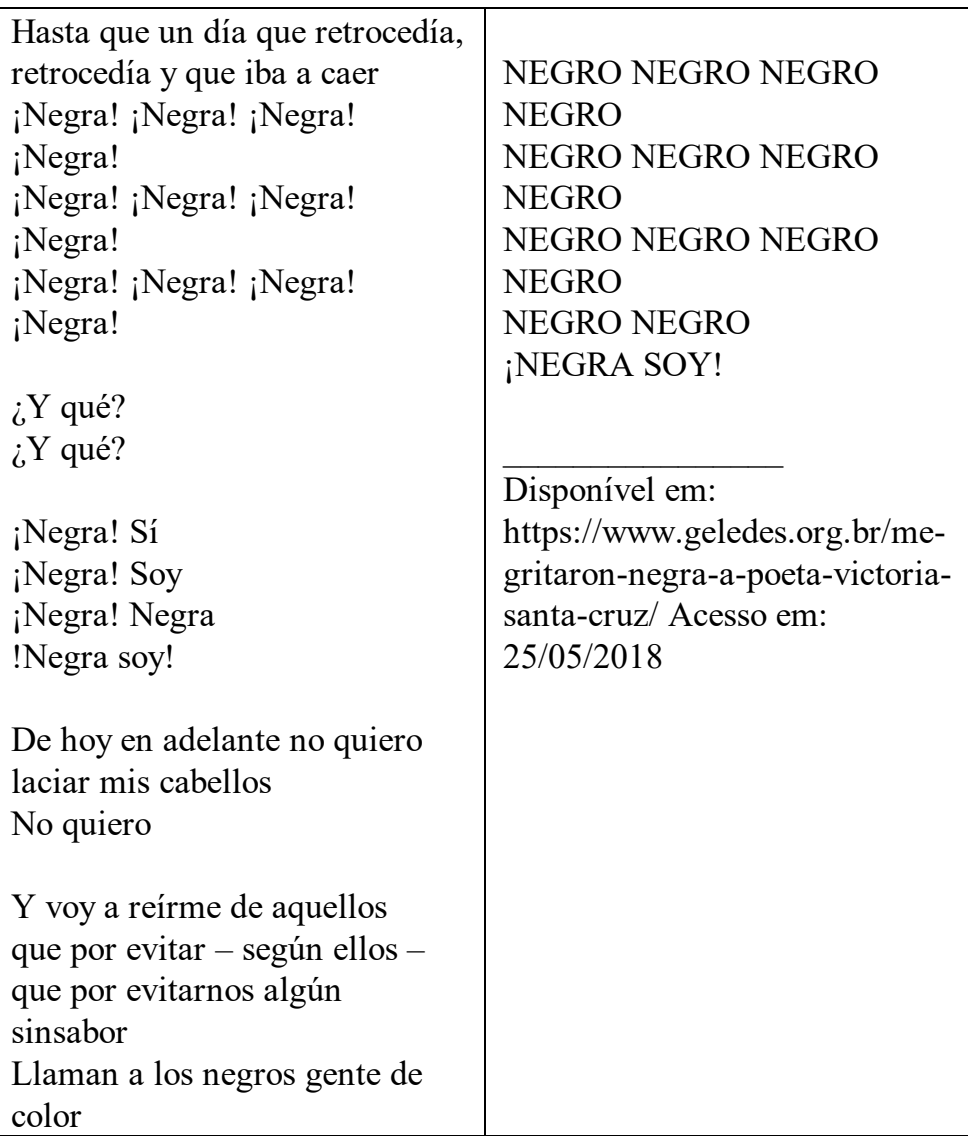

1 - “De pronto unas voces en la calle me gritaron ¡Negra!” (2 $2^{a}$ estrofa) ¿Qué sentido asume la expresión "negra" en este contexto?

2 - “Soy acaso negra?” - me dije / ¿Qué cosa es ser negra?” (3 $3^{a}$ estrofa) ¿Por qué imaginas que el yo-lírico, en este momento, tiene dificultades para reconocerse como negra?

3 - "Y me sentí negra, / Como ellos decian / Y retrocedi/ Como ellos querían." (3a estrofa)

a) ¿A quiénes se refiere el yo-lírico cuándo dice "ellos"?, esto es, ¿quiénes serían "ellos"?

b) ¿Qué significa sentirse negra de la manera como ellos querían?

4 - Dentro del relato del poema, ¿por qué imaginas que hay la repetición del verbo "retroceder”?

"Y retrocedí iNegra!/ Y retrocedí... (4 ${ }^{a}$ estrofa)

"Hasta que un día que retrocedía, I retrocedía y que iba a caer." ( $7^{a}$ estrofa)

5 - El poema se divide en dos momentos distintos: el momento en que el yo-lírico demuestra tristeza al reconocerse como negra y el momento en que el yo-lírico afirma su identidad racial con orgullo.

¿A partir de que versos del poema se inicia la trasformación de perspectiva del yo-lírico respecto a su identidad? Entresaca estos versos del texto.

6 - “¡Negra! Sí / ¡Negra! Soy / ¡Negra! Negra / Negra soy” (9ª estrofa) ¿Qué sentido asume la expresión "negra” en este contexto del poema?

7 - Como se puede observar en el poema, existe un cambio en la manera de escribir la palabra “negra/o". ¿Qué sentido se cría a partir del cambio en la grafía?, esto es, ¿qué se subentiende de ahí? 


\begin{tabular}{|l|l|}
\hline ¡Negra! ¡Negra! ¡Negra! ¡Negra! & NEGRO NEGRO NEGRO NEGRO \\
¡Negra! ¡Negra! ¡Negra! ¡Negra! & NEGRO NEGRO NEGRO NEGRO \\
¡Negra! ¡Negra! ¡Negra! ¡Negra! & NEGRO NEGRO NEGRO NEGRO \\
& NEGRO NEGRO \\
& iNEGRA SOY! \\
$\left(5^{\mathrm{a}} \mathrm{y} 7^{\mathrm{a}}\right.$ estrofas $)$ & $\left(11^{\mathrm{a}} \mathrm{y} 14^{\mathrm{a}}\right.$ estrofas $)$ \\
\hline
\end{tabular}

8 - "Y voy a reirme de aquellos, / que por evitar - según ellos -/ que por evitarnos algún sinsabor/ Llaman a los negros gente de color."

a) ¿A quién se refiere el pronombre subrayado "me"?

b) ¿A quiénes se refiere el pronombre subrayado "nos"?

c) ¿Por qué imaginas que el yo-lírico va a reírse de aquellos que usan la expresión "gente de color"?

9- El cambio de perspectiva del yo-lírico respecto a su identidad se observa por la oposición entre dos campos semánticos distintos presentes en el poema: tristeza X orgullo.

Observa los ejemplos y rellena el recuadro con estas oposiciones de sentimientos, actitudes y visiones del yo-lírico. Toma como base los ejemplos.

\begin{tabular}{|c|c|}
\hline TRISTEZA & ORGULLO \\
\hline “Soy acaso negra?" & "iNegra! Sí / iNegra! Soy” \\
\hline "retrocedí” & "avanzo segura” \\
\hline & \\
\hline & \\
\hline & \\
\hline
\end{tabular}

10- Lee las palabras de la filósofa Djamila Ribeiro y contesta a las cuestiones siguientes.

\section{TEXTO 2}

"O conceito de beleza é uma construção social. O racismo está na base desta construção. Por isso, afirmar a nossa beleza em uma sociedade racista, que de diferentes modos destrói a nossa autoestima, não é apenas uma questão de vaidade. É um ato de resistência."

Djamila Ribeiro

Disponível em: https://www.facebook.com/djamila.ribeiro.1 Acesso em: 25/05/2018

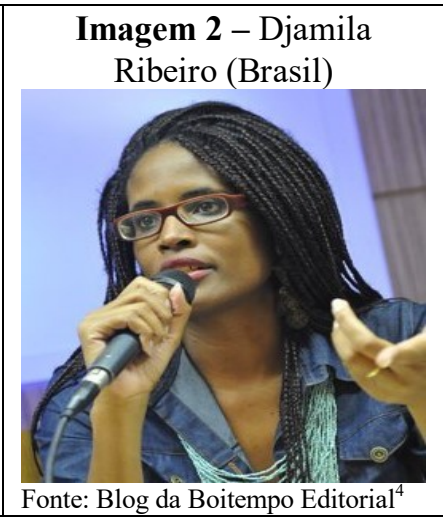

a) Máster en Filosofia Política, Djamila Ribeiro afirma que el racismo está en la base de aquello que socialmente se considera bello. ¿Estás de acuerdo con esta afirmación? Justifica.

b) ¿Crees que el yo-lírico de la poesía "Me gritaron negra" sufre el racismo existente en el concepto de belleza? Justifica tu respuesta y utiliza fragmentos del poema para darle base.

c) ¿Por qué imaginas que la afirmación de la belleza negra en las sociedades racistas es, como dice Djamila Ribeiro, un acto de resistencia?

11- ¿Sabes quiénes son estas mujeres? Todas ellas tienen gran importancia en la literatura de

\footnotetext{
${ }^{4}$ Disponível em: https://blogdaboitempo.com.br/sobre/ Acesso em: 30 maio. 2020
} 
Latinoamérica. Investiga sobre ellas y escribe un pequeño fragmento de texto sobre sus trayectorias, como en el ejemplo.

\begin{tabular}{|l|l|}
\hline $\begin{array}{c}\text { Imagen 3-Victoria } \\
\text { Santa Cruz (Perú) }\end{array}$ & Ejemplo: \\
Victoria Santa Cruz fue una gran voz del arte negro peruano. \\
Compositora, coreógrafa, diseñadora e investigadora de las culturas de la \\
raíz africana. \\
Nació el 26 de octubre de 1922 en La Victoria, provincia de \\
Lima, y murió el 30 de agosto de 2014 . Su padre fue escritor y \\
dramaturgo y su madre provenía de una familia muy vinculada a la \\
pintura, tenía 10 diez hermanos. Junto a uno de ellos ayudó a fundar una \\
compañía de teatro llamada Cumanana.
\end{tabular}

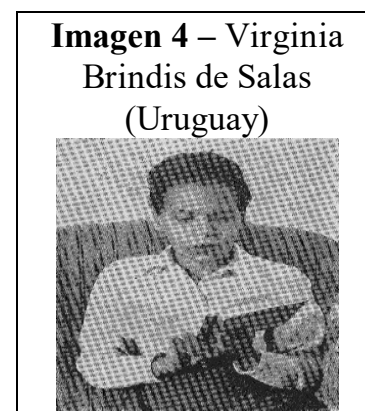

Fuente: Wikipédia ${ }^{6}$

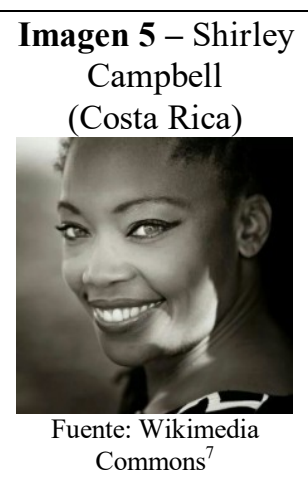

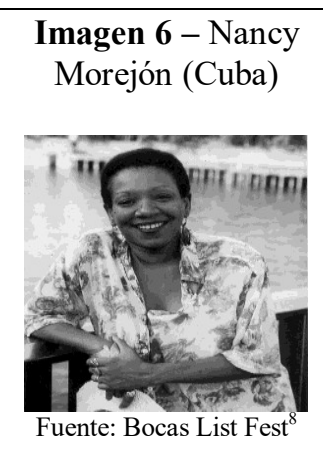

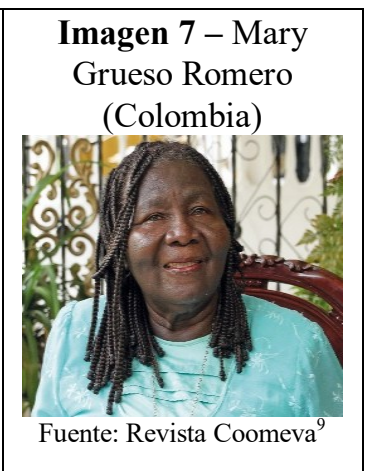

12- Investiga poemas de las cuatro escritoras de arriba y elije uno de estos, que a ti te guste, para escribirlo en tu cuaderno.

Entendemos que as retomadas, tanto dos textos, quanto das perguntas do exercício, serão fundamentais para que o leitor analise a pertinência das noções que embasam e justificam os propósitos da tarefa. Sendo assim, exposta a atividade, nos debruçaremos agora, como já adiantado, sobre as possibilidades de compreensão do poema. Com isso, poderemos melhor explicitar os vínculos entre análise interpretativa, questões propostas e objetivos.

No começo do poema, temos um eu-lírico que menciona sua infância: "Tenía siete años apenas / apenas siete años. / Que siete años / No llegaba a cinco siquiera." Este ponto de partida é de grande importância para interpretarmos a sutileza dos emaranhados de significação do texto. É ainda na infância que os sujeitos negros, de modo geral, percebem a existência da discriminação pela cor. Esta percepção ocorre, sobretudo, no início das relações com os outros, ou seja, fora do ambiente familiar. Não por acaso nos diz o eu-lírico que "unas voces en la calle / me gritaron negra." A rua, isto é, la calle, assume aqui um sentido amplo, logrado pela metáfora poética. A rua seria o convívio social. Assim, junto ao convívio social nascido na infância, surge também o contato com as visões pejorativas sobre negras e negros.

\footnotetext{
${ }^{5}$ Disponível em: https://www.youtube.com/watch?v=g52jzCTUKXA Acesso em: 30 maio. 2020

${ }^{6}$ Disponível em: https://pt.wikipedia.org/wiki/Virginia_Brindis_de_Salas Acesso em: 30 maio. 2020

${ }^{7}$ Disponível em: https://commons.wikimedia.org/wiki/File:Shirley_Campbell.jpg Acesso em: 30 maio. 2020

${ }^{8}$ Disponível em: https://www.bocaslitfest.com/author/nancy-morejon/ Acesso em: 30 maio. 2020

${ }^{9}$ Disponível em: https://revista.coomeva.com.co/ Acesso em: 30 maio. 2020
} 
A questão número 1 solicita a interpretação da expressão negra formulada nesse contexto. Já nos primeiros versos da poesia, é possível observar que tal expressão, gritada na rua, transfigura uma concepção depreciativa da negritude com a qual o eulírico entrará em contato de maneira recorrente ao estar em convívio social. Desse modo, os sentidos ofensivos criados no âmbito das ideologias racistas são incorporados ao relato deste eu-lírico.

\footnotetext{
Para pensar sobre o corpo negro, é preciso lembrar dos corpos não negros. De que corpo negro estamos falando? O corpo negro surge como uma criação do colonizador, é um corpo desumano, desprovido de alma. Ora, o corpo é uma manifestação da consciência, não existe fora das relações com outros corpos. Um corpo se cria a partir da construção do outro, do que significa para o outro (SOBRAL, 2017, p. 256).
}

A cultura latino-americana nasce sem que os negros tenham posse sobre seus corpos. Assim, o corpo negro como patrimônio colonial, pode ser violado, explorado e subalternizado. ¿Soy acaso negra? / ¿Qué cosa es ser negra?, em relação às perguntas do eu-lírico, as palavras supracitadas de Cristiane Sobral nos são fundamentais, pois reiteram que as imagens de si, criadas por homens e mulheres negras, surgem atravessadas por essa criação do colonizador presente na genética social. A questão número 2, portanto, tem por objetivo gerar reflexão quanto a essas proposições.

Assim, a poesia de Victoria Santa Cruz torna-se perspicaz ao incorporar metaforicamente tais relações. Por isso, se diz: "Y me senti negra / como ellos decían.". Nesse contexto, a autoimagem inferiorizante é incorporada pelo eu-lírico. Com as perguntas da questão de número 3, nos interessava explorar tal entendimento junto aos alunos. Sendo a palavra negra substância desta mesma identidade, admitida como insulto, nos importava observar o sujeito negro compreendido também como produto de experiências sociais diversas que significam a questão racial em nossa história.

"Y retrocedí / Y retrocedí.". Nos depararmos, neste momento, com um eu-lírico que, percebendo-se fisicamente como negra, adere às visões distorcidas naturalizadas sobre sua identidade, inserindo-se num suposto lugar de inferioridade racial pregado pelo racismo. O eu-lírico retrocede, retrocede, retrocede... Nesse sentido, compreendemos que esta interpretação de si, tendo como uma das nuances a negação da estética, também perpassa a negação de sua história, da cultura e dos conhecimentos essencialmente negros.

A repetição do verbo retroceder mimetiza tanto a repetição da vivência do racismo como a reiteração deste recuo/rejeição por parte dos sujeitos negros frente aos diversos signos que, histórica e simbolicamente, constituem esta identidade: práticas, costumes, crenças, saberes. A partir das atitudes em relação aos sinais da estética negra, o poema de Victoria Santa Cruz, de forma magistral, politiza a raça. A questão número 4 pode auxiliar no entendimento de que, com a repetição da metáfora do recuo, a lírica tece uma das possíveis posturas do sujeito negro diante das relações de poder.

"Y odié mis cabellos / Y mis labios gruesos/ Y miré apenada mi carne tostada...". Fenótipos e cabelo fazem parte de um mesmo bloco. Desse modo, o poema analisado pelos estudantes demonstra que os lábios e o cabelo não são elementos neutros dentro do conjunto corporal. Compreendendo que eles foram convertidos, pela cultura, em marcas de pertencimento raciais, observamos o eu-lírico feminino rejeitar os sinais que imprimem a negritude em seu corpo. Isso explica a atitude apontada nos versos a 
seguir: "Me alacié el cabello / Me polveé la cara." Nesse momento, o texto traz para a reflexão um assunto particularmente caro às meninas e às mulheres negras: a tentativa de controle de suas características, devido ao desejo de aproximação a padrões estéticos brancos.

Ao pensar o que define o corpo negro regulado e o corpo negro emancipado, Nilma Lino Gomes $(2017$, p.94) aponta que "o corpo negro ganha visibilidade social na tensão entre adaptar-se, revoltar-se ou superar o pensamento racista que o toma por erótico, exótico e violento." Tais aspectos estão presentes na poesia de Victoria Santa Cruz, posto que a denúncia do racismo ocorrerá juntamente à denúncia das estruturas de controle do corpo feminino negro. Tais noções devem ser discutidas em sala, além de aprofundadas a partir dos enunciados da questão de número 10.

Com as perguntas da questão 10 , nosso objetivo também é evidenciar o diálogo existente entre os discursos de diferentes autoras latino-americanas. Apesar de uma utilizar a linguagem literária e a outra não, apesar de escreverem em tempos diferentes e serem de distintos países da América Latina, a poeta Victoria Santa Cruz e a filósofa Djamila Ribeiro sintetizam a mesma problemática, apontando para a unidade das questões que levantam e contribuindo para o entendimento de que existe relação entre as "vozes negras femininas." Através de um assunto que costuma ser bastante sedutor aos adolescentes, observamos que a redefinição do padrão dominante de beleza convoca uma mensagem política de fortalecimento racial e de protesto contra a opressão.

Victoria Santa Cruz realiza, no campo da literatura, uma tradução poética das teorias e interpretações críticas suscitadas sobre a temática racial. Verificamos que a ocorrência da palavra negra/negro no poema liga-se diretamente aos estágios de autopercepção do eu-lírico, que caminha desde a inconsciência em relação à sua identidade, passando pela rejeição desta, até uma "virada de chave" - repleta de orgulho. Assim, seu texto é capaz de metaforizar aquilo que muitos de nós negros já experimentamos em relação à vivência da nossa negritude.

Desse modo, em contraposição às conotações depreciativas presentes na primeira metade do poema, conotações estas advindas do discurso etnocêntrico racista, o texto opera a ressemantização positiva da palavra negra/negro. Com uma linguagem aparentemente simples, mas que na realidade foi cuidadosamente elaborada, Victoria Santa Cruz desvela o ser negro numa posição totalmente adversa à anterior, numa postura orgulhosa e bastante afrontosa às faces do racismo.

Diante da repetição da voz que insiste em qualificá-la como negra, a certa altura do poema, o eu-lírico responde em forma de pergunta “¿Y qué? / ¿Y qué?” (E daí? / E daí?). Assim, a indagação funda o início de uma mudança de postura do eu-lírico frente à sua identidade, e a questão 5 pretende estimular esse tipo de percepção. Afinal, muito da postura emancipatória deve-se a este movimento de questionar.

Indagar os discursos socialmente construídos, o conhecimento científico, a ideologia eurocêntrica, as interpretações colonizadas etc. significa dinamizar e recriar os conhecimentos sobre o mundo, sobre o outro e sobre si. Estes versos apontam para o papel educativo das perguntas. São os questionamentos que, sintetizados na frase "¿Y qué?", tornam-se capazes de desnaturalizar o domínio e a lógica do poder.

Os significados construídos na poesia de Victória Santa Cruz refletem os embates de vozes sobre a percepção da negritude. O racismo não é um fenômeno biológico, mas discursivo. Como bem pontua Grada Kilomba (2019, p.157), o racismo funciona "através de uma cadeia de palavras e imagens que se tornam associativamente 
equivalentes, mantendo identidades em seu lugar." Conforme vemos, a partir da linguagem poética, Me gritaron negra realiza uma revisão desses lugares discursivos.

A partir da indagação do eu-lírico, que inaugura a segunda parte do poema, vemos a ressignificação poética e conceitual dos sujeitos negros realizada pelos próprios negros. A pergunta de número 6 é realizada de modo que o estudante consolide esta percepção, tendo em vista que a identidade negra não é mais interpretada como empecilho e sim como triunfo, o que também ficará explícito na sequência do poema. A ressignificação da palavra negra/negro mimetiza a ressignificação da raça, da tradição e de seus paradigmas.

Nas versões escritas, verificamos que a grafia do termo se transforma. Este detalhe não pode passar despercebido pelos estudantes. A questão de número 7 busca levá-los ao entendimento de que na linguagem poética muitos são os elementos que se articulam na produção de sentidos. Assim, na primeira metade da poesia, enquanto o reconhecimento da negritude é admitido pelo eu-lírico como insulto inferiorizante, a palavra negra/negro segue grafada em letras minúsculas. Na segunda metade do poema, agora diante de um eu-lírico afirmativo e orgulhoso de si, a palavra negro apresenta-se em legras garrafais.

Retoma-se a estética. Assim, os traços físicos, antes rejeitados pelo eu-lírico, já que eram considerados como desprovidos de beleza, adquirem outro sentido; são vistos como belos e assumidos como marca de uma identidade agora festejada: "de hoy en adelante no quiero/laciar mis cabellos/ no quiero/y voy a reirme de aquellos/ que por evitar - según ellos - / que por evitarnos algún sinsabor/Llaman a los negros gente de color" Com os enunciados A e B da questão de número 8 , os estudantes devem ser capazes de perceber que o eu-lírico, apesar de realizar um relato em primeira pessoa, se introduz numa vivência coletiva, metáfora da experiência de todos os sujeitos negros.

Considerando a linguagem como produtora de realidades não neutras, compreendemos que a expressão "gente de color" insere-se em um contexto racista, uma tentativa de "eufemismo" para aquilo que fora tomado como defeito para a perspectiva branca. $\mathrm{O}$ exercício $\mathrm{C}$ da questão número 8 busca destacar esta problematização engendrada na poesia.

"Al fin compreendi/ ya no retrocedo/ y avanzo segura/ avanzo y espero (...) Al fin comprendi// ya tengo la llave”. Imbuída de uma nova compreensão de si, o eu-lírico se retira e retira toda a população negra deste lugar de suposta inferioridade racial, cantando afirmativamente a negritude. Vale pontuar o caráter subversivo do texto de Victoria Santa Cruz. A própria oposição entre "retrocedí" e "avanzo segura" elucida a subversão aí presente. A questão de número 9 pretende explorar esses dois polos semânticos da poesia, pois, rompendo com os discursos hegemônicos e com as interpretações sociais negativas sobre os negros, sua história e cultura, o eu-lírico apresenta uma série de atitudes antagônicas àquelas anteriores.

Dessa forma, além de ressignificar a noção de negritude, o poema elabora os sentidos de resistência e de [re] existência negras. Assim, terminamos o texto com um eulírico que, ao confrontar as vozes dando-lhe nova resposta, passa não só a perceber-se de forma diferente, mas também existe de outro modo, por isso [re]existe. E este existir de outro modo assume um movimento de luta e desobediência combativa às estruturas racistas: resistência. Uma resistência sustentada pelas metáforas do corpo e do grito orgulhoso "negra soy". 
Ao sugerir uma nova representação para o corpo feminino negro, a poesia de Victoria Santa Cruz cria novas e inventivas possibilidades de referências imagéticas e temáticas sobre a negrura dentro do cenário da literatura. Entretanto, essa atitude também é empreendida por muitas outras literatas negras. Como enfatiza Mirian Cristina dos Santos (2018, p.160), trata-se de "uma postura bastante próxima a do pensamento feminista negro, a qual consistiria em ideias de mulheres negras, produzidas por e para mulheres negras." Nosso objetivo com as questões de número 11 e 12 é fomentar o interesse dos estudantes sobre a vida e a produção literária de outras poetas afro-latinas de atitude semelhante, tendo em vista a legitimação das mulheres como sujeitos intelectuais, algo por vezes negado dentro e fora da escola.

Victoria Santa Cruz e as demais autoras que constam na tarefa apontam de modo recorrente para as percepções sociais em torno dos sinais culturais e estéticos da negritude. Tais sinais, tornados repulsivos pela lógica branca colonizada, são tematizados em seus trabalhos literários e reinterpretados como características de uma identidade constantemente positivada. Com essa atividade, as mulheres negras são lidas como corpos simbólica e fisicamente agredidos pelo racismo. Entretanto, são esses mesmos corpos os capazes de desmantelar a opressão e de gerar novos discursos. Nossos estudantes devem compreender que a literatura também é espaço em que reflexões críticas se dão. Questionar, desafiar e descontruir as percepções colonialistas são comportamentos que nossos alunos dos Institutos Federais precisam desenvolver e que a EPT deve favorecer.

\section{Considerações Finais}

Compreendemos que estudantes do ensino médio não são leitores especialistas, portanto, seria incoerente esperar respostas que desenvolvessem de modo profundo as possibilidades de desdobramentos interpretativos que aqui expomos sobre o poema de Santa Cruz. No entanto, este artigo tem professores de Espanhol como principal públicoalvo, capazes de compreender os matizes imbricados nas sugestões das questões. Observamos, ao longo do desenvolvimento da atividade, que as respostas dos estudantes, embora mais simples, costumam contemplar a compreensão da poesia. Cabe à/ao docente, quando necessário, intervir, acrescentar ou esmiuçar leituras, a fim de mediar as reflexões junto aos alunos.

O trabalho com este poema sempre proporciona um profícuo debate em sala de aula, com discussões que evidenciam a primazia de noções eurocêntricas de mundo introjetadas na sociedade. Ao longo da interpretação poética, os educandos discorrem sobre a revalorização negra e problematizam, conscientemente, as visões sociais construídas a respeito dos signos da negritude, ultrapassando, na maioria das vezes, a questão estética, que é a mais explicita no texto e a geradora da discussão. Assim, para além da desnaturalização do padrão de beleza, um importante ponto desta tarefa está na possibilidade de os alunos tematizarem a independência e a descolonização dos olhares, atitude que deve ser levada a cabo em todas as esferas do ser e do saber.

No poema de Vitoria Santa Cruz, assim como na poética das outras autoras sugeridas como pesquisa, o corpo feminino negro é pensado dentro de um contexto histórico, social e cultural que, mais do que peruano, colombiano, cubano ou brasileiro, é afro-latino. Quando fizemos menção à identidade afro-latina, não tivemos a pretensão de defini-la ou de teorizar conceitos acerca desta. Nosso objetivo foi explicitar que, de certo 
modo, negras e negros da América Latina e Caribe "falam" de um lugar muito semelhante, de modo que as aulas de E/LE podem tornar perceptíveis a proximidade desses discursos.

Compreendemos que a literatura é também uma forma de nós, negras e negros, existirmos e de nos [re]conhecermos. Se, como pondera Bella Jozef (2007, p.14), "as literaturas da América Latina podem ser pensadas em função de um mesmo contexto geral”, isso significa admitir que as produções de autoria afro-latina podem estabelecer diálogos entre si ao abordarem a existência negra na diáspora. Oportunizar o contato com produções de escritoras e escritores negros de países vizinhos é parte da necessidade de submergir o aprendiz/leitor nessa literatura que, apesar dos possíveis contatos, ainda parece apartada ou desconhecida da nossa cultura afrodescendente.

A professora de Literatura Latino-americana, Miriam Victoria Gomes, citada pelo Portal Geledés (2015), aponta para o "desaparecimento artificial" do negro em contexto latino-americano. Segundo a estudiosa, este "desaparecimento artificial" está relacionado ao abafamento de temáticas caras a negras e negros, bem como à omissão deliberada de sua presença nos livros, nos meios de comunicação, na educação e, por que não dizer, na literatura. Insistir na visibilidade desta autoria e, mais especificamente, da autoria feminina afro-latina nas aulas de Espanhol na EPT é também um ato político, uma forma de ansiar por transformação da realidade, um modo de romper com o apagamento instaurado para aquelas e aqueles que há tempos estiveram subalternizadas/os.

No entanto, consideramos importante salientar que esta visibilidade não pode ocorrer apenas quando a negritude é tematizada. Como enfatizado muitas vezes até aqui, é preciso que a escola afirme negras e negros na posição de sujeitos, o que requer admitir a universalidade desta identidade, isto é, significa apresenta-las/los na condição de indivíduos ativos nas mais diversas áreas, gerando saberes e artes de caráter variados, teorizando sobre diferentes assuntos, desde os que possuem direta relação com o existir negro, aos demais. Tal empenho também importa para que nossas/os estudantes negras/os latino-americanas/os não sejam forçadas/os a identificarem-se com outras/os brancas/os, mas consigo mesmas/os (cf. KILOMBA, 2019).

Afro-latinas e afro-latinos participam da formação deste continente e constroem incomensuráveis patrimônios materiais e imateriais nas Américas. Reconhecer isso é reconhecer o lugar da autoria negra nas aulas de E/LE, tanto na produção literária, aludida neste artigo, quanto para além dela. Portanto, pensar politicamente a nossa prática pedagógica na EPT implica colaborar para que o ensino-aprendizagem de nossa disciplina seja cada vez mais emancipador, contra hegemônico, descolonizado e antirracista.

\section{Referências}

ALEIXO, I. O que a autobiografia de Angela Davis nos ensina sobre racismo epistêmico no Brasil? Portal Geledés, 2019. Disponível em: https://www.geledes.org.br/ Acesso em: 29 mar. 2020

BRASIL. Diretrizes Curriculares nacionais para Educação das Relações Étnico-raciais e para o Ensino de História e de Cultura Afro-brasileira e Africana. Brasília: MEC, 2004. 
. Lei 10.639 de 9 de janeiro de 2003. D.O.U. de 10 de janeiro de 2003.

. Orientações Curriculares Nacionais para o Ensino Médio: Linguagens, códigos e suas tecnologias. Brasil: MEC, 2006.

. Parâmetros Curriculares Nacionais: terceiro e quarto ciclos do Ensino Fundamental. Língua Estrangeira. Brasília: MEC, 1998.

BRASIL, M. Superar as diferenças para encontrar-se no outro. Anuario brasileño de estudios hispánicos. Madrid: Embajada de España en Brasil, n. 1 p. 19-24 abr. 2007.

CRUZ, V. S. Me gritaron negra. Disponível em: https://www.youtube.com/watch?v=cHr8DTNRZdg Acesso em: 30 mar. 2020

"Black and Woman": entrevista com Victoria Santa Cruz realizada pela

Odin Teatre. Disponível em: <https://www.youtube.com/watch?v=p6Frs9rDWx8>. Acesso em: 29 mar. 2020.

FERRREIRA, R. A. A importância de Victoria Santa Cruz na construção da identidade da mulher negra. Jornal da USP/ Rádio USP, 2016. Disponível em: https://jornal.usp.br/ Acesso em: 10 de abr. 2020.

FUNDAÇÃO PALMARES. Diáspora africana, você sabe o que é? Disponível em: http://www.palmares.gov.br/?p=53464 Acesso em: 30 mar. 2020.

GOMES, M. V. "Desaparecimento artificial": entrevista com Miriam Victoria Gomes. In: MORAES, M. Estrangeiros no próprio país: a história dos afro-argentinos. Portal Geledés. 2015. Disponível em: https://www.geledes.org.br/ Acesso em: 29 mar. 2020.

GOMES, N. L. O Movimento Negro educador: saberes construídos nas lutas por emancipação. $1^{\mathrm{a}}$ ed. Petrópolis: Vozes, 2017.

hooks, b. Olhares Negros: raça e representação. Trad. Stephanie Borges. $1^{\mathrm{a}}$ ed. São Paulo: Elefantes, 2019.

JOZEF, B. Brasil e América Latina: práticas culturais e considerações sobre o ensino de espanhol. Anuario brasileño de estudios hispánicos. Madrid: Embajada de España en Brasil, n. 1 p. 11-18 abr. 2007.

KILOMBA, G. Memórias da Plantação: episódios de racismo cotidiano. Trad. Jess Oliveira. $1^{\mathrm{a}}$ ed. Rio de Janeiro: Cobogó, 2019.

MORAES, M. Estrangeiros no próprio país: a história dos afro-argentinos. Portal Geledés. 2015. Disponível em: https://www.geledes.org.br/ Acesso em: 29 mar. 2020 
MARTINS, V. Gritaram-me negra: a vida e a arte de Victoria Santa Cruz. Jornal Alma Preta Online, 2017. Disponível em: https://www.almapreta.com/ Acesso em 29 abr. 2020.

PARAQUETT, M. Prefácio. In: ZOLIN-VESZ, F. (org.). A (In)visibilidade da América Latina na formação do professor de espanhol. Campinas: Pontes Editores, 2013, p. 912.

RIBEIRO, D. O que é lugar de fala? $1^{\mathrm{a}}$ ed. Belo Horizonte: Letramento: Justificando, 2017.

SANTOS, A. C. El texto literario y sus funciones en la clase de E/LE: de la teoría a la práctica. Anuario brasileño de estudios hispánicos. Madrid: Embajada de España en Brasil, n. 1 p. 33-46 abr. 2007.

SANTOS, M. C. Políticas do corpo na prosa de Cristiane Sobral. In: Intelectuais Negras: prosa negro-brasileira contemporânea. Rio de Janeiro: Malê, 2018, p. 159-225.

. A Literatura enquanto espaço de luta. In: SANTOS, M. C. Intelectuais Negras: prosa negro-brasileira contemporânea. Rio de Janeiro: Malê, 2018, p. 227234.

SHIROMA, E.; LIMA FILHO, D. L. Trabalho docente na Educação Profissional e Tecnológica e no Proeja. Educação e Sociedade, Campinas, vol. 32, n. 116, p. 725-743, jul-set. 2011.

SOBRAL, C. "Quem não se afirma não existe": entrevista com Cristiane Sobral. In: FREDERICO, G; MOLLO, L. T.; DUTRA, P. Q. Estudos de Literatura Brasileira Contemporânea. Brasília, n. 51, maio/ago. 2017, p. 254-258.

Recebido em 31 de maio de 2020

Aceito em 20 de julho de 2020 